consisting of developers, industrialists, agricultural representatives, environmentalists, businessmen, and representatives from Government and the two universities.

Actor Robert Redford initiated the programme, commenting: 'For five years now I have believed it would be in the national interest to develop a strong, broad-based programme that will provide sound training for those who will manage the nation's resources... I have been seeing two dire positions develop that are false - two extreme points of view - and there's a need to be able to get a balanced, orderly approach to our environment that recognizes both the need for development and our responsibility to protect our resources', Redford told a group of WSU and UI administrators at a special meeting held earlier this year in Moscow, Idaho, adding: 'This will be a programme where managers and students can develop the technical knowledge and management skills necessary to meet the needs of a growing nation while at the same time providing effect- ive stewardship of the resources upon which our nation depends'.

By combining talents and information from all of the fields of study that specifically deal with our resources-forestry, mining agricultural and water resources, nuclear energy, biology, business and economics, and others, on both campuses-'we can provide well for the future of the nation'.

Hope Moore, of Washington, D.C., Executive Director of the Institute, was formerly Associate Director for the Cultural Program in the U.S. Department of the Interior. She said that WSU and UI were selected because of the strength of their programmes, the proximity of the two institutions, and their location close to a wide variety of natural resources and industries.

\section{News Service \\ Washington State University Pullman \\ Washington 99163, U.S.A.}

\title{
African Countries Sign Environmental Agreements
}

In Abidjan, Ivory Coast, on 23 March of this year, sixteen coastal countries of West and Central Africa unanimously approved a treaty to protect their lengthy coastline and coastal waters from pollution. They also agreed on a protocol committing them to cooperate in pollution emergencies such as a massive spill of oil or a toxic chemical, and endorsed an Action Plan of environmental assessment and environmentally-sound development.

'An ambitious programme like this requires solid financing', declared Raimi O. Ojikutu, Director of the Environmental Division of the Nigerian Federal Ministry of Housing and the Environment: Nigeria has made a very substantial effort and I am happy to note that the other 15 Governments present have also assumed their financial responsibilities'.

The African States pledged US $\$ 2.5$ millions to be paid in 1982 and 1983 into a special regional trust-fund, while the sponsor of the plenipotentiary conference, the United Nations Environment Programme (UNEP), promised $\$ 1.4$ million during the next three years, starting this year. Nigeria, the biggest country in the region which stretches from Mauritania to Namibia, will contribute the largest single sum-around $\$ 550,000$.

Senegal pointed out that oil tankers sometimes clean their tanks in one country's territorial waters and, when espied, flee to safety in another's territorial waters. The 16 countries, several of which, including Gabon, the Ivory Coast, and Senegal, were represented by cabinet ministers, then approved 'a right of hot pursuit' resolution to allow naval vessels of one country to give chase to offending tankers in another's waters. Even if 'hot pursuit' may not always prove feasible, the resolution does create a political basis for catching tankers, and may make oil tanker captains think twice before doing something illegal.

Signatories of the environmental treaty 'recognize the threat to the marine and coastal environment, its ecological equilibrium, resources, and legitimate uses, posed by pollution and by the absence of an integration of an environmental dimension into the development process'. They also acknowledge 'the need for coopera- tion among the [signatories] in order to ensure sustainable, environmentally-sound development through a coordinated and comprehensive approach'.

The preamble to the treaty stresses the need for a carefully planned research, monitoring, and assessment, programme in view of the scarcity of scientific information on marine pollution in the West and Central African Region'. Six kinds of pollution are specifically mentioned in the treaty: discharge or dumping from ships, pollution from such land-based sources as industrial effluents, agricultural run-off and sewage, pollution from exploration and exploitation of the sea-bed and its 'subsoil', atmospheric pollution, and coastal erosion.

The African environmental treaty will enter into force when the Parliaments of six States have ratified it, which is expected to take about two years. 'This is an historic and quite unprecedented act of West and Central African unity, solidarity, and cooperation', said Lamine Fadika, Ivory Coast Minister of Marine, who chaired the conference.

Of the 20 states invited to the Abidjan conference, the 16 that attended were Angola, Benin, Cameroon, Congo, Equatorial Guinea, Gabon, Gambia, Ghana, Guinea, Ivory Coast, Liberia, Mauritania, Nigeria, Senegal, Togo, and Zaire. The four absent countries were Cape Verde, Guinea-Bissau, Sao Tome and Principe, and Sierra Leone.

Dr Mostafa K. Tolba, UNEP's Executive Director, hailed the signing of the treaty as the fourth link in UNEP's Regional Seas network of Action Plans for ten seas. After the Mediterranean, the Kuwait Region, and the Red Sea and Gulf of Aden, now West and Central Africa.' Action Plans have also been adopted recently for the Caribbean and East Asia.

\author{
Paul Evan Ress \\ European Regional Information Officer \\ United Nations Environment Programme \\ Avenue Jean-Tremblay 16 \\ Petit-Saconnex \\ 1211 Geneva 10, Switzerland.
}

